\title{
Baseline Dietary Restraint Predicts Negative Treatment Outcomes after 12 Months in Children and Adolescents with Obesity Participating in a Lifestyle Intervention
}

\author{
Özgür Albayrak ${ }^{a}$ Wilfried Pott ${ }^{c, d}$ Johannes Hebebrand ${ }^{b}$ \\ Martina de Zwaan ${ }^{a}$ Ursula Pauli-Pott ${ }^{c}$ \\ ${ }^{a}$ Department of Psychosomatic Medicine and Psychotherapy, Hannover Medical School, \\ Hannover, Germany; ${ }^{\mathrm{b}}$ Department of Child and Adolescent Psychiatry, Psychosomatics and \\ Psychotherapy, University Hospital Essen, University of Duisburg-Essen, Essen, Germany; \\ 'Department of Child and Adolescent Psychiatry, Psychosomatics and Psychotherapy, \\ Faculty of Human Medicine, Philipps University Marburg, Marburg, Germany; ${ }^{d}$ Department \\ of Psychosomatic and Psychiatry, Red Cross Children's Hospital Siegen, Siegen, Germany
}

\section{Keywords}

Eating behavior - Treatment - Psychotherapy · Weight reduction · Youth

\begin{abstract}
Objective: Current lifestyle interventions for children and adolescents with obesity often exclude patients with an eating pathology, leaving the impact of eating pathologies on treatment outcomes largely unconsidered. We investigated the predictive value of disordered eating symptoms on BMI z-score reduction in a sample of 111 German children and adolescents with overweight (90th percentile $\leq \mathrm{BMI}<97$ th percentile) and obesity (BMI $>97$ th percentile) aged 7-15 years in an outpatient lifestyle intervention program. Methods: We defined a BMI $z$-score reduction of more than $5 \%$ after 12 months as a successful outcome. Disordered eating symptoms (i.e., dietary restraint, emotional eating, external eating, and binge eating) were assessed at baseline with the Eating Pattern Inventory (EPI-C) and the "bulimia" scale of the Eating Disorder Inventory (EDI-2). Covariates were: baseline z-BMI, age, gender, and maternal education level. Results: Multiple regression analysis revealed that dietary restraint significantly predicted change in BMI z-scores between baseline and T1. Higher levels of dietary restraint were associated with a lower BMI Z-score reduction between T0 and T1. To compare non-completers with completers on the 4 eating behavior scales, we used MANCOVA. At baseline, children who subsequently dropped out of the program prematurely showed significantly higher dietary restraint scores than children who completed the intervention, irre-
\end{abstract}


spectively of their gender, age, and BMI z-score at baseline and their mother's education level. Discussion: Our results provide further evidence that the analysis of treatment processes in lifestyle intervention programs for children and adolescents with overweight and obesity should take into account a broader multidimensional approach including eating and dietary habits.

\section{Introduction}

Overweight and obesity are frequent and steadily increasing health problems in childhood and adolescence $[1,2]$. Although obesity, eating disorders, and unhealthy weight practices are interrelated [3], systematic evaluations of obesity treatment programs have not sufficiently addressed disordered eating behavior in children and adolescents as an outcome predictor, not least because eating pathology is often part of the exclusion criteria of obesity treatment programs, which makes it difficult to know if it would have had an impact on treatment outcomes [4]. The available studies were obviously mainly designed to determine the benefit of intervention programs in terms of weight reduction [4]. According to a systematic Cochrane review, behavioral lifestyle interventions combining physical activity, dietary attitudes, and behavioral changes compared to standard care or self-help can produce a significant and clinically meaningful weight reduction in children and adolescents who are overweight [5]. This statement was supported by a more recent review, although the magnitude of weight loss was discussed critically [6]. Only single studies have examined the role of eating disorder symptoms in weight gain prevention and weight loss treatment programs [7-9]. In a Belgian study, 122 inpatients aged 7-17 years adhering to an obesity treatment program were characterized with respect to eating disorder symptoms (Eating Disorder Examination), global self-worth (Self-Perception Profile for Children), and psychopathological symptoms (Child Behavior Checklist). Eating disorder symptoms (e.g., dietary restraint, eating concerns, weight concerns, shape concerns, and total number of binges) negatively predicted weight loss as a treatment outcome at the 2-year follow-up [8]. In a sample of 27 children with overweight and obesity, those with a BMI $>95$ th percentile had the greatest concerns about weight and shape [9]. Within this small sample, children who were more concerned about their body shape at baseline had larger decreases in percent of body weight between pretreatment and posttreatment after 10-12 weekly sessions of a family-based intervention. Although shape concerns were related to short-term weight change, there was no relation between dietary restraint, shape, weight, or eating concerns and weight change between the end of treatment and the follow-up visit 8 months later [9].

Based on these inconsistent findings and given that the prevalence of eating disorder symptoms in children who are overweight has increased [10,11], we hypothesize that a higher level of disordered eating behavior (i.e., dietary restraint, emotional eating, external eating, and binge eating) would predict a lower BMI z-score reduction in a 1-year long outpatient life-style intervention program for weight reduction in children and adolescents.

\section{Materials and Methods}

\section{Participants}

One hundred eleven children and adolescents with overweight and obesity (56 boys) aged between 7 and 15 years (mean \pm SD: $11.05 \pm 1.97$ years), who had been referred for 
Table 1. Description of the sample

\begin{tabular}{lc}
\hline Characteristic & Value \\
\hline Subjects, $n$ & 111 \\
Age, years & $11.05 \pm 1.97$ \\
$\quad$ Range & $8.0-15.0$ \\
Gender & \\
$\quad$ Male & $56(50.9)$ \\
Female & $55(49.5)$ \\
BMI & $29.42 \pm 4.26$ \\
Range & $21.7-48.9$ \\
BMI z-score & $2.49 \pm 0.41$ \\
Range & $1.47-3.47$ \\
Maternal educational level & \\
No educational qualification & $6(5.4)$ \\
Primary school/general secondary school & $29(26.1)$ \\
Middle school/junior high school & $50(45.0)$ \\
Highschool/College & $17(15.3)$ \\
No reply & $9(8.1)$ \\
Paternal educational level & \\
No educational qualification & $1(0.9)$ \\
Primary school/general secondary school & $41(36.9)$ \\
Middle school/junior high school & $27(24.3)$ \\
High school/college & $19(17.1)$ \\
No reply & $23(20.7)$ \\
\end{tabular}

Values are presented as means \pm SD or numbers (\%) unless otherwise stated.

weight reduction treatment by a local pediatrician (Table 1) were included. Inclusion criteria were BMI $\geq 97$ th age- and sex-related percentile [12], or BMI $\geq 90$ th percentile, but with further risk factors (e.g., hypertension, dyslipidemia, and orthopedic problems), and regular school attendance.

\section{Procedure}

To analyze whether baseline eating behavioral variables can be used to predict weight change at the 12-month follow-up in children and adolescents who attend a "best-practice" routine-care lifestyle intervention ("Fit Kids") [13], we conducted a longitudinal analysis with 2 assessment waves, i.e., at baseline (T0: within 3 weeks before the start of the intervention) the body weight and height of the participants and questionnaires pertaining to eating behavior were assessed, and at the conclusion of the program (T1: 1 year after T0) the body weight and height of the participants were reassessed. The psychological assessment was performed by a trained psychiatrist or psychologist and included the "bulimia" scale of the German version of the Eating Disorder Inventory (EDI-2) and the assessment of dietary restraint, emotional eating, and external eating with the Eating Pattern Inventory (EPI-C). If patients displayed clinically relevant eating disorder pathology, they were referred for specialized treatment.

The outpatient lifestyle intervention "Fit-Kids" for children and adolescents with overweight and obesity is a routine care program (certified by the German Obesity Association) that is based on the evidence provided by Summerbell et al. [14], the outpatient lifestyle intervention program by Reinehr et al. [13], and the guidelines of the German Nutrition Society [15]. The program has been described in detail elsewhere [16]. In short, the program combines behavioral therapy for eating and physical activity behaviors, physical exercise, and dietary 
Albayrak et al.: Baseline Dietary Restraint Predicts Negative Treatment Outcomes

courses. The families are continuously involved. The program consists of 2 phases. The intervention phase lasts 3 months and comprises (1) behavioral therapy sessions, (2) a dietary training course, (3) a parents' course to facilitate transfer into everyday family life, and (4) a physical exercise course for children and adolescents. Each course is $90 \mathrm{~min}$ in duration and takes place once every 2 weeks. During the 3 months the families visit the hospital-based program once a week for two 90-min sessions, each. The second phase lasts 9 months. It consists of a physical activity course once a week and a parent group once a month. The study protocol was approved by the ethics committee of the University Medical Centre, Giessen. Children and parents agreed to participate in this study. Parents gave their written informed consent. The study protocol follows the suggestions of the Declaration of Helsinki.

\section{Variables}

Body weight and height were measured with patients in underwear using a calibrated scale (digital column scale SECA 701) and a wall mounted stadiometer (SECA 222). BMI z-scores were calculated on the basis of German reference data for children [12] using the least mean square method by Cole [17], which normalizes the resulting distribution. A BMI z-score reduction $\geq 5 \%$ has repeatedly been shown to be predictive of a significant reduction of physical risk factors $[18,19]$.

Binge eating was assessed dimensionally using the bulimia scale of the EDI-2 [20]. Internal consistencies (Cronbach's $\alpha$ ) in 13- to 18-year-old adolescent patients with eating disorders and 2 control groups were $0.95,0.77$, and 0.78 , respectively [21], indicating an adequate reliability of the scale in adolescents. Convergent validity was excellent. The scale differentiated well between patients and controls [21]. In the present study we used the scale in children. To analyze internal consistencies in our subsample of children aged 7-12 years $(n=78)$, we calculated Cronbach's $\alpha$, which was 0.86 , indicating a good reliability that exceeds the coefficient in healthy adolescents [21]. We also analyzed the convergent validity of the scale in the complete sample by calculating the correlation coefficients with the EPI-C scales (see below). The correlation coefficients of the bulimia scale with the EPI-C emotional, external, and restraint eating scales were $0.73(p<0.001), 0.72(p<0.001)$, and $0.34(p<0.001)$, respectively.

For the assessment of dietary restraint, emotional eating, and external eating, the EPI-C [22] was used. The EPI-C is a self-report questionnaire for children and adolescents with scales that show good internal consistencies (Cronbach's $\alpha$ between 0.74 and 0.93 ). The "emotional eating" scale assesses eating in response to feelings of loneliness, disappointment, and unhappiness (e.g., "eating helps me when I am disappointed"). The "dietary restraint" scale refers to weight concerns and attempts to eat less to reduce weight or to not gain more weight (e.g., "when I have finished eating I worry about getting too fat"). The "external eating" scale measures eating in response to external cues (e.g., "when I see food, I get hungry right away, even if it is not mealtime yet").

\section{Treatment Outcome}

Treatment outcome was defined as the change in BMI z-scores between baseline (T0) and the end of the program (T1). Of the 111 participants, however, 21 children dropped out of the program prematurely (those children attended the program for less than 6 months). To consider these drop-outs (non-completers) in the analyses, we additionally compared these non-completers with the completers of the program.

\section{Statistical Analysis}

To analyze the study hypothesis hierarchical multiple regression analyses were conducted. The BMI z-score at the end of the program was used as the criterion variable and the eating behavior scales as predictor variables. We controlled for the BMI z-score at base- 
Table 2. Prediction of weight loss by the eating behavior scales

\begin{tabular}{|c|c|c|c|c|c|c|c|c|}
\hline \multirow{2}{*}{$\begin{array}{l}\text { Step/ } \\
\text { model }\end{array}$} & \multirow[t]{2}{*}{ Variable(s) entered } & \multirow[t]{2}{*}{$R_{\text {adj }}^{2}$} & \multicolumn{3}{|c|}{ Change statistics } & \multicolumn{3}{|l|}{ Model 3} \\
\hline & & & $R_{\text {adj }}^{2}$ & $F$ & $p$ & $\begin{array}{l}\beta \text { coeffi- } \\
\text { cient }\end{array}$ & $t$ & $p$ \\
\hline 1 & $\begin{array}{l}\text { Age, gender, maternal } \\
\text { educational level }\end{array}$ & 0.12 & 0.12 & 3.43 & 0.021 & & & \\
\hline 2 & Baseline BMI z-score & 0.80 & 0.68 & 254.05 & 0.000 & & & \\
\hline 3 & Dietary restraint & 0.81 & 0.01 & 5.03 & 0.028 & 0.11 & 2.24 & 0.028 \\
\hline 3 & Emotional eating & 0.80 & 0.00 & 0.01 & 0.931 & 0.05 & 0.92 & 0.931 \\
\hline 3 & External eating & 0.80 & 0.00 & 0.85 & 0.360 & -0.00 & -0.09 & 0.360 \\
\hline 3 & Bulimia & 0.81 & 0.01 & 3.88 & 0.053 & 0.10 & 1.97 & 0.053 \\
\hline
\end{tabular}

line, age, gender, and maternal education level. Controlling for the BMI z-score at baseline led to analysis of the prediction of "change" in the BMI z-score between baseline and the end of the intervention. To meet the assumptions of the statistical analyses the rank scaled variable maternal education level was transformed into a dichotomous variable using a median split. In an additional drop-out analysis we compared the non-completers of the program with the completers in the 4 eating behavior scales using MANCOVA. Post hoc comparisons of the single scales in case of a significant overall effect were performed, controlling for age, gender, maternal education level, and the BMI z-score at baseline.

\section{Results}

\section{Sample Characteristics}

The mean $( \pm \mathrm{SD})$ baseline BMI and BMI z-score of the 111 children and adolescents with obesity were $29.42 \pm 4.26$ and $2.49 \pm 0.41$, respectively. Twenty-one patients dropped out during the program. At the end of the program, the mean $( \pm \mathrm{SD}) \mathrm{BMI}$ and BMI z-score of the 90 completers were $27.91 \pm 3.81$ and $2.18 \pm 0.51$, respectively.

\section{Associations of Potential Confounding Variables with the BMI z-Score Outcome}

We found no statistically significant association between gender and change in BMI $\mathrm{z}$-score between baseline and the end of the program $(r=0.03)$. Maternal education level, however, significantly predicted the change in the BMI z-score $(r=-0.30, p<0.006)$. The higher the education level of the mother, the more the BMI z-score decreased until the end of the program. Furthermore, we found age to be marginally associated with a reduction of the BMI z-score at T1 $(r=-0.21, p<0.051)$.

\section{Prediction of Weight Loss by Eating Behavior}

We used multiple hierarchical regression analyses to analyze whether the eating behavior scales predicted a change in the BMI z-score between baseline and the end of the program. In the regression analyses maternal education level, age, gender, and the baseline BMI z-score of the child were included in the regression model in a first step in order to control for the influences of these variables. In a second step, the 4 eating behavior scales were included. The 4 scales together explained the significant variance in the outcome criterion over and above the variables that were included in the first step $\left(R^{2}{ }_{\text {adj }}=0.031, F=3.19, p=0.018\right)$. In 4 consecutive regression analyses we tested each of the effect of the 4 eating scales (Table 2). Dietary 
Albayrak et al.: Baseline Dietary Restraint Predicts Negative Treatment Outcomes

Table 3. Comparison of eating behavior scales between noncompleters and completers of the program

\begin{tabular}{|c|c|c|c|c|c|}
\hline \multirow[t]{2}{*}{ Scale } & \multirow{2}{*}{$\begin{array}{l}\text { Range of } \\
\text { possible } \\
\text { scores }\end{array}$} & \multirow{2}{*}{$\begin{array}{l}\text { Children/adolescents } \\
\text { who completed the } \\
\text { program }(n=90)\end{array}$} & \multirow{2}{*}{$\begin{array}{l}\text { Children/adolescents } \\
\text { who dropped out of } \\
\text { the program }(n=21)\end{array}$} & \multicolumn{2}{|c|}{ ANCOVA } \\
\hline & & & & $F$ & $p$ \\
\hline Dietary restraint ${ }^{1}$ & $8-32$ & $21.76(4.84)$ & $27.12(6.48)$ & 15.24 & $<0.001$ \\
\hline Emotional eating ${ }^{1}$ & $4-16$ & $6.55(3.66)$ & $5.76(2.68)$ & 0.40 & 0.527 \\
\hline External eating ${ }^{1}$ & $5-20$ & $10.22(4.25)$ & $10.35(3.55)$ & 0.09 & 0.765 \\
\hline Bulimia $^{2}$ & $6-24$ & $10.20(4.46)$ & $10.65(5.52)$ & 0.40 & 0.530 \\
\hline
\end{tabular}

Values are presented as means $\pm \mathrm{SD}$, adjusted for age, gender, baseline BMI z-score, and maternal educational level. ${ }^{1}$ Schacht et al. [22]. ${ }^{2}$ Paul and Thiel [20].

restraint significantly predicted change in BMI z-score between baseline and T1 ( $\beta=0.11$, $\left.R_{\text {adj }}^{2}=0.01, F=5.03, p=0.028\right)$. Higher levels of dietary restraint at baseline were associated with a lower BMI z-score reduction between $\mathrm{T} 0$ and $\mathrm{T} 1$. Emotional eating, external eating, and binge eating were not significantly associated with change in the BMI z-score. However, there was a trend with regard to the association of binge eating and BMI z-score reduction ( $p=$ 0.053; Table 2), indicating that higher levels of binge eating are associated with a lower BMI z-score reduction.

\section{Comparison between Non-Completers and Completers with Regard to Eating Behavior}

We used MANCOVA to analyze the differences between the non-completers and the completers in the 4 eating behavior scales. Multivariate $F$-statistics proved to be statistically significant, indicating a difference in the 4 scales (Wilks $\lambda=0.833, F=4.46, p<0.003$ ). Post hoc ANCOVAs revealed that the dietary restraint scale contributed most to the overall difference $(F=15.24, p<0.001, d=0.96)$. At baseline, children who subsequently dropped out of the program showed significantly higher dietary restraint scores than children who completed the intervention, irrespectively of their gender, age, and BMI z-score at baseline and their mother's education level. Groups did not differ in terms of emotional eating, external eating, or binge eating (Table 3).

\section{Discussion}

We aimed to analyze whether disordered eating behavior predicted successful completion of a 12-month lifestyle intervention in a clinical outpatient sample of children and adolescents with overweight and obesity. We found that dietary restraint negatively predicted weight reduction at the end of the program. This result held after exclusion of the drop-outs and considering the pre-post difference of the continuous BMI z-score, as well as when comparing non-completers with completers of the program.

Studies on eating behavior as a predictor of the treatment outcome in a lifestyle intervention in children and adolescents with obesity are scarce [8, 9]. However, our result is in line with the study of Braet [8], who found dietary restraint and shape/weight concerns to predict a worse weight loss outcome. In a sample of 27 children with overweight and obesity [9] using the Children's Eating Disorder Examination, Levine et al. [9] found that children who were more concerned about their body shape at baseline lost more weight after 10-12 weeks of a family-based lifestyle intervention. Dietary restraint, however, did not predict weight loss. 
The reason for our result is unclear. It is important to note that measures of dietary restraint fail to predict an actual lower caloric intake and thus are not valid measures of caloric restriction [23]. Instead, dietary restraint refers to the cognitive effort to restrict food, regardless of the behavioral outcome of this effort [24]. The items of the dietary restraint scale of the EPI-C [22] were more closely aligned with the rigid control dimension of dietary restraint (i.e., all-or-nothing approach to dieting) rather than the flexible control dimension (i.e., a more graduated approach to dieting, in which "fattening" foods are eaten in limited quantities without the feeling of guilt) [25]. Higher flexible restraint, but not rigid restraint, has been shown to significantly predict a $5 \%$ weight loss posttreatment [26]. According to prospective studies, dietary restraint in children has been associated with the risk of onset of obesity, indicating that dietary restraint could signify inefficient weight-loss attempts of a child $[27,28]$. In the study of Schacht et al. [22], dietary restraint was the only dimension that was associated with a higher BMI. Alternatively, increases in dietary restraint may represent an attempt to control weight in response to weight gain [24]. Of note, there is no study available that has compared the EPI-C dietary restraint scale with other measures of dietary restraint.

Another explanation for our observation is that chronic dietary restraint may be associated with chronic negative emotions, such as frustration or anger [29, 30]. Dietary restraint may also be linked to loss of control eating, which could result in an increased intake of highcalorie food that consequently could promote accumulation of body fat [31]. As reported previously, we did not find an association between dietary restraint and depressive symptoms, and depressive symptoms did not predict weight reduction [32].

Studies about adulthood obesity lifestyle intervention programs have shown conflicting results regarding dietary restraint as a predictor of treatment outcome [33-37]. An inverse relation of dietary restraint and weight loss was reported in a sample of 478 adults with obesity who were treated with sibutramine [35]. In a double-blind placebo-controlled 4 -month study of 80 women with obesity (age $43.9 \pm 10.6$ years) with sibutramine $(10 \mathrm{mg} /$ day) or placebo, low dietary restraint scores showed a trend toward predicting a better treatment outcome [36]. Similarly, Teixeira et al. [37] found that lower levels of self-reported previous dieting at baseline prior to a 16-month lifestyle intervention independently predicted successful completion. Moreover, in a large-scale study on weight loss maintenance after a group-based lifestyle intervention, a larger weight loss was predicted by fewer previous weight reduction attempts [38].

In contrast to these findings, Dalle Grave et al. [33] found that increased dietary restraint predicted a positive treatment outcome in a sample of 500 Italian adults with obesity. Delahanty et al. [34] found that increased dietary restraint predicted successful end-of-study weight loss in 16 weekly sessions of a diabetes prevention program in a sample of 274 adults. The conflicting results might point to not-yet-identified moderator variables, such as social data, different assessment methodologies of dietary restraint, and different treatment settings. These results should encourage researchers to conduct studies on the predictive value of eating behavior dimensions for the treatment outcome of lifestyle interventions in children and in adolescents.

Interestingly, none of the other eating behavior subscales (e.g., emotional eating and external eating [EPI-C] and binge eating [EDI-2]) predicted treatment outcome. Only single studies investigated the role of binge eating in obesity [11,39-41]. In the study of Levine et al. [9], loss of control over eating was not predictive of treatment outcome (i.e., weight loss). In line with the study of Levine et al. [9], binge eating did not predict treatment outcome in our sample, either.

Based on findings from longitudinal epidemiological studies, dieting and unhealthful weight control behaviors were shown to predict higher BMI increments as compared to 
adolescents who did not show such behaviors [42]. Among the clinical studies that aimed to investigate the predictive value of disordered eating behavior on treatment outcomes [7-9], none was directly comparable to our study due to different methodological approaches, e.g., different questionnaires had been used to assess disordered eating symptomatology, choice of intervention (e.g., inpatient vs. outpatient treatment program), long versus short-term measurement (i.e., 2 years at follow-up), and differences in the mean age of the samples.

Currently, most treatment programs focus on weight reduction as the primary treatment outcome. Since children and adolescents are subject to changes in body fat composition, growth, hormonal status, behavioral and emotional characteristics, and eating habits, treatment outcome variables other than pure effects on body weight (i.e., increase or decrease) should be taken into account (i.e., habitual physical activity or healthy eating) [5]. In this respect, our study adds valuable information for clinicians and dietary professionals to consider disordered eating behavior symptoms in the behavioral treatment of children and adolescents with obesity.

Our study has several limitations. First, the effect of dietary restraint on the BMI z-score change between baseline and T1 was small $\left(\beta=0.11, R_{\text {adj }}^{2}=0.01\right)$. This small effect raises the question of how relevant dietary restraint might be in the clinical context. However, it is essential to bear in mind that children and adolescents participating in weight loss treatment constitute a heterogeneous group in terms of eating behaviors and pathology, meaning that there are only a few children who show meaningful eating problems. Moreover, besides eating behaviors, there are many other variables which influence weight loss in treatment programs. Thus, one cannot expect to explain a large amount of variance by dietary restraint in this heterogeneous group. Nevertheless, we have shown in our post hoc analysis that children who subsequently dropped out from the program had significant higher scores of dietary restraint than children who regularly completed the program $(F=$ $15.24, p<0.001, d=0.96)$. Here, the effect size was large. In our understanding, it is important to identify this at-risk group, i.e., obese children and adolescents reporting dietary restraint at the start of a weight loss intervention. In future research, large homogeneous samples with a well-defined eating pathology should be analyzed in order to cross-validate our results and precisely study the effects of dietary restraint and other eating pathology dimensions on BMI z-score change. Further limitations comprised the small study group. In addition, we did not assess dietary habits, body composition, or basal metabolic rate, which would have allowed us to estimate the treatment outcome more precisely than with the BMI $z$-score alone. The definition of treatment outcome in this study is in line with other studies; however, it could have been less unidimensional. In future studies, aspects of the treatment outcome, such as dietary habits, physical activity, and choice of food, should be additionally considered.

\section{Conclusion}

We showed that dietary restraint at baseline was associated with unsuccessful weight reduction after 12 months in a best practice lifestyle intervention program for children and adolescents. Evaluation and development of weight reduction programs should take into account eating psychopathological symptoms. The definition of success of a lifestyle intervention for children and adolescents with obesity should be extended from mere weight reduction to behavioral and psychological improvements, including eating and dietary habits. Specifically, it is essential to identify the rigid control dimension of dietary restraint, i.e., allor-nothing approach to dieting, because this might contribute to the development of an eating disorder pathology. Thus, behavioral treatment programs should be tailored to children with 
(rigid) dietary restraint, which would enable these patients and their families to learn techniques to modify dietary restraint and to overcome the need to strictly control their eating habits in order to avoid the development of pathological dietary restraint.

\section{Acknowledgement}

We thank all of the participants and their parents for their contributions to this study.

\section{Statement of Ethics}

All of the subjects (or their parents or guardians) gave their written informed consent.

The study protocol was approved by the research institute's committee on human research.

\section{Disclosure Statement}

The authors have no conflict of interests to declare.

\section{Funding Sources}

There is no funding source to be declared for this study.

\section{Author Contributions}

U.P.P. and W.P. planned this study. Ö.A. and W.P. conducted this study. U.P.P. and Ö.A. conducted the analyses and wrote this article. J.H. and M.d.Z. contributed to the writing.

\section{References}

1 Kalies H, Lenz J, von Kries R. Prevalence of overweight and obesity and trends in body mass index in German pre-school children, 1982-1997. Int J Obes Relat Metab Disord. 2002 Sep;26(9):1211-7.

2 Wang Y, Beydoun MA. The obesity epidemic in the United States-gender, age, socioeconomic, racial/ethnic, and geographic characteristics: a systematic review and meta-regression analysis. Epidemiol Rev. 2007; 29(1):6-28.

3 Irving LM, Neumark-Sztainer D. Integrating the prevention of eating disorders and obesity: feasible or futile? Prev Med. 2002 Mar;34(3):299-309.

4 Carter FA, Bulik CM. Childhood obesity prevention programs: how do they affect eating pathology and other psychological measures? Psychosom Med. 2008 Apr;70(3):363-71.

5 Oude Luttikhuis H, Baur L, Jansen H, Shrewsbury VA, O'Malley C, Stolk RP, et al. Interventions for treating obesity in children. Cochrane Database Syst Rev. 2009 Jan;(1):CD001872.

6 Mühlig Y, Wabitsch M, Moss A, Hebebrand J. Weight loss in children and adolescents. Dtsch Arztebl Int. 2014 Nov;111(48):818-24.

7 Epstein LH, Paluch RA, Saelens BE, Ernst MM, Wilfley DE. Changes in eating disorder symptoms with pediatric obesity treatment. J Pediatr. 2001 Jul;139(1):58-65.

8 Braet C. Patient characteristics as predictors of weight loss after an obesity treatment for children. Obesity (Silver Spring). 2006 Jan;14(1):148-55.

9 Levine MD, Ringham RM, Kalarchian MA, Wisniewski L, Marcus MD. Overeating among seriously overweight children seeking treatment: results of the children's eating disorder examination. Int J Eat Disord. 2006 Mar; 39(2):135-40. 
Albayrak et al.: Baseline Dietary Restraint Predicts Negative Treatment Outcomes

10 Burrows A, Cooper M. Possible risk factors in the development of eating disorders in overweight preadolescent girls. Int J Obes Relat Metab Disord. 2002 Sep;26(9):1268-73.

11 Decaluwé V, Braet C. Prevalence of binge-eating disorder in obese children and adolescents seeking weightloss treatment. Int J Obes Relat Metab Disord. 2003 Mar;27(3):404-9.

12 Kromeyer-Hauschild K, Wabitsch M, Kunze D, Geller D, Geiss HC, Hesse V, et al. Percentiles of body mass indx in children and adolescents evaluated from different regional German studies. Monatsschr Kinderheilkd. 2001;149(8):807-18.

13 Reinehr T, Kersting M, Wollenhaupt A, Alexy U, Kling B, Ströbele K, et al. Evaluation of the training program “OBELDICKS" for obese children and adolescents. Klin Padiatr. 2005 Jan-Feb;217(1):1-8.

14 Summerbell CD, Ashton V, Campbell KJ, Edmunds L, Kelly S, Waters E. Interventions for treating obesity in children. Cochrane Database Syst Rev. 2003;(3):CD001872.

15 Deutsche Adipositas-Gesellschaft, Deutsche Diabetes Gesellschaft, Deutsche Gesellschaft für Ernährung, Deutsche Gesellschaft für Ernährungsmedizin [Internet]. Interdisziplinäre Leitlinie der Qualität S3 zur „Prävention und Therapie der Adipositas“ - Version 2.0. Available from: www.awmf.org/leitlinien/detail/ ll/050-001.html.

16 Pott W, Albayrak O, Hebebrand J, Pauli-Pott U. Treating childhood obesity: family background variables and the child's success in a weight-control intervention. Int J Eat Disord. 2009 Apr;42(3):284-9.

17 Cole TJ. The LMS method for constructing normalized growth standards. Eur J Clin Nutr. 1990 Jan;44(1): 45-60.

18 Reinehr T, Andler W. Changes in the atherogenic risk factor profile according to degree of weight loss. Arch Dis Child. 2004 May;89(5):419-22.

19 Reinehr T, Kiess W, Kapellen T, Andler W. Insulin sensitivity among obese children and adolescents, according to degree of weight loss. Pediatrics. 2004 Dec;114(6):1569-73.

20 Paul T, Thiel A. Eating Disorder Inventory-2. Deutsche Version. Göttingen: Hogrefe; 2005.

21 Salbach-Andrae H, Schneider N, Bürger A, Pfeiffer E, Lehmkuhl U, Holzhausen M. [Psychometric properties of the Eating Disorder Inventory (EDI-2) in adolescents]. Z Kinder Jugendpsychiatr Psychother. 2010 May;38(3): 219-28.

22 Schacht M, Richter-Appelt H, Schulte-Markwort M, Hebebrand J, Schimmelmann BG. Eating Pattern Inventory for Children: a new self-rating questionnaire for preadolescents. J Clin Psychol. 2006 Oct;62(10):1259-73.

23 Stice E, Sysko R, Roberto CA, Allison S. Are dietary restraint scales valid measures of dietary restriction? Additional objective behavioral and biological data suggest not. Appetite. 2010 Apr;54(2):331-9.

24 Schaumberg K, Anderson DA, Anderson LM, Reilly EE, Gorrell S. Dietary restraint: what's the harm? A review of the relationship between dietary restraint, weight trajectory and the development of eating pathology. Clin Obes. 2016 Apr;6(2):89-100.

25 Westenhoefer J, Stunkard AJ, Pudel V. Validation of the flexible and rigid control dimensions of dietary restraint. Int J Eat Disord. 1999 Jul;26(1):53-64.

26 Blomquist KK, Grilo CM. Predictive significance of changes in dietary restraint in obese patients with binge eating disorder during treatment. Int J Eat Disord. 2011 Sep;44(6):515-23.

27 Field AE, Austin SB, Taylor CB, Malspeis S, Rosner B, Rockett HR, et al. Relation between dieting and weight change among preadolescents and adolescents. Pediatrics. 2003 Oct;112(4):900-6.

28 Stice E, Cameron RP, Killen JD, Hayward C, Taylor CB. Naturalistic weight-reduction efforts prospectively predict growth in relative weight and onset of obesity among female adolescents. J Consult Clin Psychol. 1999 Dec;67(6):967-74.

29 Goldschmidt AB, Tanofsky-Kraff M, Goossens L, Eddy KT, Ringham R, Yanovski SZ, et al. Subtyping children and adolescents with loss of control eating by negative affect and dietary restraint. Behav Res Ther. 2008 Jul; 46(7):777-87.

30 Goossens L, Braet C, Bosmans G. Relations of dietary restraint and depressive symptomatology to loss of control over eating in overweight youngsters. Eur Child Adolesc Psychiatry. 2010 Jul;19(7):587-96.

31 Tanofsky-Kraff M, Yanovski SZ, Schvey NA, Olsen CH, Gustafson J, Yanovski JA. A prospective study of loss of control eating for body weight gain in children at high risk for adult obesity. Int J Eat Disord. 2009 Jan;42(1): 26-30.

32 Pott W, Albayrak O, Hebebrand J, Pauli-Pott U. Course of depressive symptoms in overweight youth participating in a lifestyle intervention: associations with weight reduction. J Dev Behav Pediatr. 2010 Oct;31(8): 635-40.

33 Dalle Grave R, Calugi S, Corica F, Di Domizio S, Marchesini G; QUOVADIS Study Group. Psychological variables associated with weight loss in obese patients seeking treatment at medical centers. J Am Diet Assoc. 2009 Dec; 109(12):2010-6.

34 Delahanty LM, Peyrot M, Shrader PJ, Williamson DA, Meigs JB, Nathan DM; DPP Research Group. Pretreatment, psychological, and behavioral predictors of weight outcomes among lifestyle intervention participants in the Diabetes Prevention Program (DPP). Diabetes Care. 2013 Jan;36(1):34-40.

35 Elfhag K, Finer N, Rössner S. Who will lose weight on sibutramine and orlistat? Psychological correlates for treatment success. Diabetes Obes Metab. 2008 Jun;10(6):498-505.

36 Hainer V, Kunesova M, Bellisle F, Hill M, Braunerova R, Wagenknecht M. Psychobehavioral and nutritional predictors of weight loss in obese women treated with sibutramine. Int J Obes. 2005 Feb;29(2):208-16. 
37 Teixeira PJ, Going SB, Houtkooper LB, Cussler EC, Metcalfe LL, Blew RM, et al. Pretreatment predictors of attrition and successful weight management in women. Int J Obes Relat Metab Disord. 2004 Sep;28(9):112433.

38 Myers VH, McVay MA, Champagne CM, Hollis JF, Coughlin JW, Funk KL, et al. Weight loss history as a predictor of weight loss: results from phase I of the weight loss maintenance trial. J Behav Med. 2013 Dec;36(6):574-82.

39 Johnson WG, Grieve FG, Adams CD, Sandy J. Measuring binge eating in adolescents: adolescent and parent versions of the questionnaire of eating and weight patterns. Int J Eat Disord. 1999 Nov;26(3):301-14.

40 Morgan CM, Yanovski SZ, Nguyen TT, McDuffie J, Sebring NG, Jorge MR, et al. Loss of control over eating, adiposity, and psychopathology in overweight children. Int J Eat Disord. 2002 May;31(4):430-41.

41 Tanofsky-Kraff M, Yanovski SZ, Wilfley DE, Marmarosh C, Morgan CM, Yanovski JA. Eating-disordered behaviors, body fat, and psychopathology in overweight and normal-weight children. J Consult Clin Psychol. 2004 Feb;72(1):53-61.

42 Neumark-Sztainer D, Wall M, Guo J, Story M, Haines J, Eisenberg M. Obesity, disordered eating, and eating disorders in a longitudinal study of adolescents: how do dieters fare 5 years later? J Am Diet Assoc. 2006 Apr; 106(4):559-68. 